\title{
Cristóvão Brito
}

Professor Adjunto do Departamento e Mestrado de Geografia,

Universidade Federal da Bahia

catbri35@yahoo.com.br

\section{Grande corporação e estruturação da região industrial e urbana nos arredores de Salvador-Ba ${ }^{1}$}

\begin{abstract}
Resumo
Ao longo da primeira metade do século XX, a formação da riqueza na Bahia dava-se de maneira muito limitada, baseada em atividades agromercantis e financeiras dependentes da generosidade da natureza e das flutuações dos preços dos produtos nos mercados estrangeiros. O Recôncavo, como núcleo histórico da base econômica baiana, refletia nos aspectos técnicos e produtivos, na infra-estrutura e na sociedade, o nível declinante das condições de vida e da geração de riqueza. É nesse ambiente que a Petrobras insere-se a partir da década de 1950 e passa a reestruturar a organização social, técnica e produtiva em torno da área onde ela produz e industrializa o petróleo e o gás natural. Como resultado disso, ao longo da segunda metade do século XX, emergiu um espaço urbano e industrial complexo nos arredores do município de Salvador.
\end{abstract}

Palavras-chave: grande corporação; desenvolvimento regional; industrialização; urbanização.

\begin{abstract}
LARGE CORPORATION AND STRUCTURING AROUND THE REGION OF INDUSTRIAL AND URBAN OF SALVADOR-BAHIA

Along the first half of the century XX the formation of the wealth in Bahia felt in a very limited way, based on "agro-mercantile" activities and financial dependents of the generosity of the nature and of the flotations of the prices of the products in the foreign markets. The Recôncavo, as historical nucleus of the economical base of Bahia, contemplated in the technical and productive aspects, in the infrastructure and in the society the declining level of the life conditions and of the wealth production. It is in that adapts that Petrobras is inserted starting from
\end{abstract}


the decade of 1950 and raising to restructure the social, technical and productive organization, around the area where the petroleum and the natural gas are produced and industrialized. As a result of that, along the second half of the century $X X$ an urban and industrial complex space emerged in the surroundings of the municipal district of Salvador.

Key-words: large corporation; regional development; industrialization; urbanization.

\section{Introdução}

A divisão espacial da produção que emergiu no início da década de 1930 no Brasil implicou o deslocamento da economia baiana para uma posição de pouco prestígio no cenário brasileiro. Esse fato deveu-se muito mais à própria condição de como foi estruturada e se desenvolvia secularmente a geração da riqueza econômica na Bahia, em bases agromercantisfinanceiras e semi-escravistas, que a uma punição ao estado da Bahia pelas forças que emergiram junto com Vargas, em 1930, e que promoveram uma política de centralização do Estado e do mercado nacionais. O comércio triangular (exterior $\Leftarrow$ exportações da Bahia $\Rightarrow$ importação de manufaturas da região Sudeste) a que a economia baiana foi submetida a partir da década de 1930 e a retenção de parte das reservas cambiais pelo Governo central, ou seja, o confisco de parte da renda em dólar obtida pelo estado da Bahia nas transações do comércio de exportação com o exterior, para financiar a industrialização no Sudeste, apenas ressaltou o papel secundário que os agentes condutores da economia baiana - os grandes comerciantes e banqueiros, sobretudo - estavam acostumados a realizar (GUIMARÃES, 1982).

Ao longo de toda a primeira metade do século XX, a economia baiana seguia sua trajetória de tendência declinante, com os capitais regionais reproduzindo-se de maneira precária e limitada, dependentes de contratações de serviços do Governo estadual (sem boas perspectivas de arrecadação financeira); de serviços extras da Petrobras, dos resultados econômicos da lavoura cacaueira, secundada pelo fumo, mamona, sisal e outros produtos primários que, embora lucrativos, dependiam das flutuações de safras e dos preços nos mercados estrangeiros. Quanto à indústria de 
transformação, em grande parte era formada de pequenas firmas, que possuíam em média quatro funcionários e que, em 1959, geraram cerca de U\$ 2.300 por estabelecimento, e apenas 1,6\% dos estabelecimentos (97 firmas consideradas sociedades anônimas) eram responsáveis pela geração de quase $70 \%$ do valor da transformação industrial, conforme dados do IBGE - Censo Industrial da Bahia de 1960.

Assim, até o final da década de 1950, subsistiam, na Bahia, zonas de atividades destacadamente agropecuárias e agroindustriais: açúcar, fumo e criação de gado (Recôncavo), cacau (Sul da Bahia), sisal e gado (Sertão), pouco prósperas, autárquicas e controladas pelos financistas e pelos grandes comerciantes sediados na cidade do Salvador. Por sua vez, a capital baiana, com sua função portuária e administrativa, servia como "cabeçade-ponte" centralizando e drenando grande parte da riqueza gerada em sua região e transferindo-a preferencialmente para o exterior, ao tempo em que servia de ponto de distribuição, em sua região, das mercadorias produzidas no Sudeste e no Sul do Brasil.

A incrível forma engenhosa de como as classes dirigentes baianas conseguiram seguir criando fortunas, sem um fundamento que provesse sua manutenção regular, apostando sempre na generosidade da natureza, na sagacidade de um ou outro comerciante e/ou banqueiro importante, sob o amparo fiscal e financeiro do Estado, dependente de contingências dos mercados estrangeiros, e secularizada na manutenção de uma horda de serviçais desvalidos, já estava esgotada no crepúsculo dos anos 1940. Pois, nesse período, a economia baiana já apresentava os limites extremos da estagnação econômica regional, que vinha se arrastando desde o final do século anterior (AZEVEDO; LINS, 1969).

O texto objetiva explicar em que condições e de que maneira foi possível emergir um espaço urbano e industrial complexo nos arredores do município de Salvador a partir da segunda metade do século $\mathrm{XX}$, em meio a uma cultura política, econômica e social baseada na tradição aristocrática, patrimonialista e escravista herdada do período anterior. 


\section{O Recôncavo à espera de sua redenção econômica}

A crise secular que ocorria no estado da Bahia atingia todo o Recôncavo, a região imediata da cidade de Salvador. O Recôncavo, região economicamente mais importante da Bahia à época, tinha sua economia baseada na produção de açúcar em grandes usinas, utilizando o latifúndio monocultor e a força de trabalho em regime quase escravista. Ao lado da zona canavieira desenvolvia-se a fumicultura e sua manufatura, nas áreas periféricas da cana-de-açúcar. Esse conjunto regional já estava em estado de declínio econômico acelerado no final da década de 1950. Para exemplificar, de 19 usinas de açúcar existentes em 1942, restava apenas nove em atividade, em 1954, e a fumicultura degringolou com a concorrência do fumo africano e a substituição dos comerciantes alemães (que dominavam os negócios do fumo na Bahia) pelos norte-americanos, após a derrota dos alemães na II Guerra Mundial (SANTOS, V., 1990).

Dessa maneira, o Recôncavo tornara-se uma "região opaca", dispersora de população (SINGER, 1981), cuja emigração se orientava das áreas rurais para as cidades e daí para a capital e para fora do estado (SANTOS, M., 1959). É nesse ambiente que o Conselho Nacional de Petróleo (CNP), fundado em 1938, se insere com a finalidade de explorar o petróleo que, como uma dádiva da natureza para a Bahia, aflorava. O CNP tinha como meta gerir e executar todas as iniciativas de produção, controle e distribuição do petróleo e seus derivados no país. Com suas ações no Recôncavo o CNP foi colocando cunhas nas clivagens expostas da estrutura política, social e econômica arcaicas ainda resistentes.

Como resultado da abundância do petróleo no Recôncavo, o Governo federal construiu uma pequena refinaria de petróleo em 1947, com capacidade para processar apenas 2.500 barris de petróleo/dia (bpd). A refinaria foi construída em Mataripe, município de São Francisco do Conde e inaugurada em 1950 com o nome de Refinaria Landulpho Alves-Mataripe (RLAM).

Já em 1951, o Governo federal desenvolvia estudos para instituir uma empresa estatal de petróleo e enviou ao Congresso Nacional (CN) o Projeto de Lei no 1.516 , que resultou na criação da Petrobras em 1953. A empre- 
sa iniciou suas operações no Recôncavo, em 1954, em substituição ao CNP que passou a ser apenas um órgão de regulação. A criação da Petrobras alimentava, nas forças políticas e econômicas regionais, esperanças de reativação da economia baiana em bases industriais mais avançadas, considerando-se que o grande acordo entre as lideranças políticas no $\mathrm{CN}$, em torno da criação da Petrobras, sugeria uma política de desenvolvimento regional por meio das ações da companhia onde ela estivesse operando e não o seu próprio enriquecimento ou investimentos concentrados numa única região.

A instalação de empreendimentos industriais geradores de sinergias não se concretizava no Recôncavo. Essa situação provocava forte insatisfação entre os grupos políticos e econômicos regionais, tendo em vista o fato de a Petrobras limitar-se à exploração e produção do óleo e do gás natural. Além disso, a refinação de óleo era bastante pequena, cerca de $10 \%$ em relação à produção de óleo, que, entre 1959 e 1960, era de cerca de 100 mil bpd, enquanto noutros estados, onde não havia matéria-prima, as refinarias existentes processavam quantidades maiores de petróleo (Tabela 1), justificadas pela importância do mercado. Em sentido semelhante situava-se a utilização do gás natural, que era quase simbólica diante da grande potencialidade de aplicação na indústria petroquímica e de fertilizantes, que ainda não havia se instalado na Bahia.

Se localmente e de maneira isolada, ao se iniciarem as explorações de petróleo no Recôncavo registraram-se algumas reações por parte dos fazendeiros e usineiros (COSTA PINTO, 1958), em outro plano, um pouco mais tarde, diante da falta de iniciativa da Petrobras em implantar indústrias na Bahia, não sem razão, o sentimento de insatisfação se generalizava no Governo estadual e em seus interlocutores regionais (banqueiros, industriais, grandes comerciantes, etc.), desejosos da participação ativa nas atividades a jusante e a montante da produção de petróleo e gás natural no Recôncavo. Esse fato tornava-se patente com a constatação de que o estado da Bahia continuava empobrecendo e sua economia subsistia com a exploração de atividades primário-exportadoras, isso, após quase duas décadas de produção e fornecimento exclusivo à nação de todo o óleo ali produzido até então. 
Tabela 1

BRASIL: REFINARIAS DE PETRÓLEO E CAPACIDADE DE REFINO (BPD) - 1959

\begin{tabular}{|c|c|c|}
\hline Refinarias & Localização/Estado & Capacidadede Refino \\
\hline Presidente Bernardes (Cubatão) & São Paulo & 93.095 \\
\hline (1) Capuava & São Paulo & 28.105 \\
\hline (1) Ipiranga & Rio Grande do Sul & 11.115 \\
\hline (1) Manguinhos & Rio de Janeiro & 9.551 \\
\hline Mataripe & Bahia & 9.105 \\
\hline (1) Manaus & Amazonas & 4.298 \\
\hline (1) Matarazzo & São Paulo & 1.012 \\
\hline (1) Uruguaiana & Rio Grande do Sul & 172 \\
\hline
\end{tabular}

Fonte: Organizada por Cristóvão Brito, com base em: SCHOR, 1959, p. 70.(1) Refinarias particulares.

A partir de 1958, com o intuito de proceder a uma reação organizada e unificada contra o arbítrio e contra as ações estritamente microeconômicas, reveladoras da falta de um programa de investimentos industriais da Petrobras no estado da Bahia, tendo em vista a natureza estatal da empresa e a crença numa atuação voltada para o desenvolvimento regional, os agentes sociais regionais, insatisfeitos com as ações da companhia, se articularam numa enérgica campanha de reação às ações da Petrobras na Bahia. O ápice dos descontentamentos teve seu efeito potencializado durante a realização da "Conferência do Petróleo para Exame dos Justos Interesses da Bahia", organizada pelo Jornal A Tarde, entre 21 e 23 de janeiro de 1959, em Salvador, com representação dos Governos dos estados da Bahia e de Sergipe, banqueiros, industriais, os parlamentares federais baianos e parlamentares convidados de outros estados, a Associação Comercial da Bahia, sindicatos de trabalhadores e patronais, intelectuais, o CNP, a Petrobras e representantes das forças armadas.

Apesar de a Petrobras ter realizado vários investimentos na Região de Produção da Bahia (RPBA), a exemplo da construção de uma rede de estradas asfaltadas na área de exploração de petróleo, da ampliação da capacidade de refino da RLAM para 10 mil bdp, da construção de uma rede de dutos e outras realizações secundárias (Quadro1), tal fato ocorria em benefício de interesses microeconômicos da empresa que se contrapunham às ações de natureza macroeconômicas, esperadas por seus interlocutores regionais, os quais tinham suas demandas postergadas e/ou preteridas pela companhia. 


\section{Quadro 1}

PRINCIPAIS OBRAS CONSTRUÍDAS PARA UTILIZACCÃO PELA PETROBRAS NA RPBA - 1955/1960

\begin{tabular}{|c|l|}
\hline Ano & Obras construídas \\
\hline \multirow{2}{*}{1955} & $\begin{array}{l}\text { - } 50 \mathrm{~km} \text { de oleoduto para conectar os campos de Miranga, } \\
\text { Água Grande e Mata; }\end{array}$ \\
\hline \multirow{2}{*}{1956} & $\begin{array}{l}\text { - } 100 \mathrm{~km} \text { de oleoduto para conectar os campos de Panelas, } \\
\text { Buracica, Taquipe e Candeias até a refinaria e ao Terminal } \\
\end{array}$ \\
$\begin{array}{l}\text { Marítimo de Madre de Deus (Temadre); - Temadre; - rodovias } \\
\text { asfaltadas; }\end{array}$ \\
\hline 1957 & $\begin{array}{l}\text { - duplicação da RLAM (de } 5 \text { mil bpd, para } 10 \text { mil bpd); } \\
\text { - } 65 \text { km de oleoduto para o Temadre; - rodovias asfaltadas; }\end{array}$ \\
\hline 1958 & - ampliação da RLAM (42,5 mil bpd); - rodovias asfaltadas; \\
\hline 1959 & - ampliação do Temadre; - ampliação da RLAM (42,5 mil bpd); \\
\hline 1960 & $\begin{array}{l}\text { - conclusão da ampliação da RLAM (42,5 mil bpd); } \\
\text { - rodovias asfaltadas. }\end{array}$ \\
\hline
\end{tabular}

Fonte: Organizado por Cristóvão Brito, com base em: Petrobras, 1975; Revista Petrobras, 1963.

\section{Os investimentos da Petrobras na Bahia e as possibilidades de criação de sinergias econômicas nos arredores de Salvador}

Entre 1960 e 1964, o novo Governo federal, de cunho populista (Jânio Quadros - 1960, e João Goulart - 1961 a 1963), buscou agir no atendimento das demandas da base social que lhe dava suporte político, fato que contribuía para definir um novo modo de relação entre a Petrobras e seus interlocutores na Bahia. A partir de então, a agenda da Petrobras no Recôncavo pautava-se na busca do atendimento dos acordos entre os agentes presentes na "Conferência do Petróleo". Os principais elementos do consenso declarados na "Carta do Petróleo" eram: majoração da taxa de royalties, de 5\% para $10 \%$, devidos pela Petrobras em favor dos municípios petrolíferos e do estado da Bahia; realização, pela Petrobras, de investimentos industriais no refino e na petroquímica; e incentivo à qualificação da força de trabalho industrial.

Em resposta a isso, ao lado dos investimentos da Petrobras, programados e em desenvolvimento em algumas partes do país, para o 
Recôncavo, foi decidido, a partir de 1961, a implantação e a operação pela companhia dos seguintes empreendimentos: uma fábrica de asfalto junto ao Terminal Marítimo de Madre de Deus (Temadre), em Candeias; o Conjunto Petroquímico da Bahia (COPEB), em Camaçari, constituído de uma fábrica de amônia e outra de uréia, para fabricação de fertilizantes nitrogenados à base de gás natural proveniente dos campos do Recôncavo; uma fábrica de gasolina natural junto à RLAM e outra em Catu para processar líquido de gás natural; novas ampliações na RLAM e demais investimentos; e a majoração do percentual da taxa de royalty destinado ao estado da Bahia, de 5\% para $8 \%$, e de $1 \%$ para $2 \%$, em favor dos municípios petrolíferos (REVISTA PETROBRAS, 1966; 1963).

A execução de todo esse investimento na área de exploração e industrialização do óleo e do gás natural na zona petrolífera do Recôncavo (Figura 1) se daria, porém, sem a participação acionária de capitais privados, o que atendia só parcialmente às demandas dos grupos empresariais regionais (banqueiros, grandes comerciantes, usineiros e outros empresários), que pleiteavam participar dos negócios do petróleo.

Mesmo com o novo ânimo esboçado pela nova orientação dos investimentos da Petrobras no Recôncavo, os grupos regionais de pressão, interessados na definição de uma nova política de atuação econômica da companhia na Bahia, não lograram os benefícios almejados, pois eles ainda continuariam por mais tempo alijados de uma atividade econômica mais robusta e de longa duração proporcionada pela Petrobras. Contudo, esses agentes eram contemplados com contratação temporária de vários tipos de serviços, desde obras civis e de montagens industriais até transporte de valores.

Se não bastasse a conjuntura de altas taxas de inflação, salários muito baixos e a ação essencialmente especulativa dos grandes capitalistas regionais, uma grande área do estado da Bahia (mais de 60\%) localiza-se nos limites de clima semi-árido (polígono das secas) sujeito a fortes e constantes secas, como as que ocorreram em 1952 e em 1958. Ao lado do fator natural negativo, porém tecnicamente contornável, colocavam-se as ações dilapidadoras dos coronéis do sertão e das demais áreas rurais e pequenas cidades articulados, por meio do voto e da clientela, à burguesia mercantil/financeira e letrada da capital (SAMPAIO, N., 1960). 
Figura 1

RPBA: DISTRIBUIÇÃO DOS CAMPOS DE PETRÓLEO E GÁS NATURAL - 1960

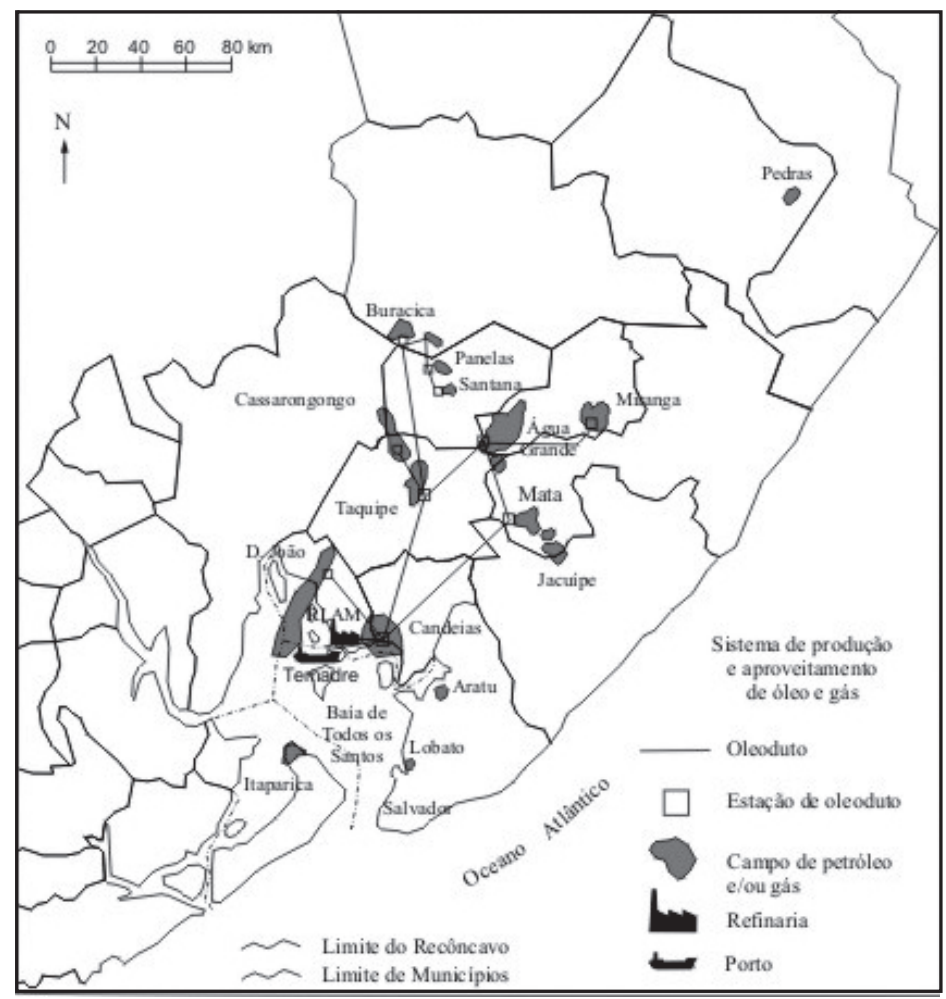

Fonte: Organizado por Cristóvão Brito, com base em: G. FERNANDES, 1958; PETROBRAS, 1975.

Nessas condições, as bases econômicas para a reprodução futura dos capitais regionais na Bahia já estavam comprometidas a priori, enredadas na aliança entre as oligarquias mercantil-financeiras e os coronéis, que reproduziam o "enigma baiano", representado pelo longo processo de letargia econômica. Todavia, o estado da Bahia não estava sozinho nesse ambiente de estagnação econômica causadora de conseqüências sociais e políticas negativas gravíssimas. Com ele também estavam os estados da "recém-descoberta região problema" - o Nordeste brasileiro -, em meio a um processo de quase convulsão social, devido ao nível de pobreza extrema. A condição de miséria empurrava as massas camponesas à organização e preparação para uma forma de ação revolucionária iminente (OLIVEIRA, 1987; COHN, 1978). 
Buscando superar as dificuldades sociais e econômicas da região Nordeste e integrá-la ao mercado nacional, o Governo federal decidiu criar, em 1959, mais um órgão de atuação exclusiva no Nordeste, a Superintendência do Desenvolvimento do Nordeste (SUDENE), para agir de maneira planejada e com recursos técnicos e econômicos suficientes ao fomento econômico da região.

Inicialmente, a ação da SUDENE previa desenvolver um processo de industrialização com a implantação de indústrias novas, principalmente siderúrgicas, e a reestruturação das já existentes, além de apoiar a agricultura em seus setores mais dinâmicos, privilegiando a elevação da produtividade e a diversificação dos produtos. Excluía-se dos propósitos da SUDENE a reforma agrária.

O I Plano Diretor da SUDENE, aprovado pelo Congresso Nacional em dezembro de 1961, trazia embutido um mecanismo financeiro importante para dar suporte à promoção dos investimentos econômicos no Nordeste, que consistia na dedução de até 50\% do imposto de renda devido pelas pessoas jurídicas de capital nacional para inversões produtivas no Nordeste. Essa proposta foi uma alternativa à extinção pelo Governo federal, no mesmo ano, do incentivo à importação estrangeira de máquinas, equipamentos e insumos industriais. Segundo Castro (1975), a proposta teve inspiração no programa de recuperação econômica aplicado em 1959, no Sul da Itália.

Durante o ano de 1962, os capitais investidos no Nordeste ainda não eram suficientes e, para isso, uma modificação na lei de incentivos fiscais da SUDENE alterou substancialmente a importância das inversões financeiras na região, com a introdução do "mecanismo 34/18". Por meio desse artifício, todas as pessoas jurídicas do país e estrangeiras com negócios no Brasil poderiam deduzir até $50 \%$ do imposto de renda devido para aplicar no Nordeste e ainda dispor de outros apoios governamentais, especialmente do Governo baiano, com a redução de $60 \%$ do Imposto sobre Circulação de Mercadorias (ICM), por cinco anos, recolhidos ao banco de Desenvolvimento do Estado da Bahia (Desembanco), para posterior reinversão na própria empresa, a fim de produzir melhorias e/ou expansão do empreendimento; outro apoio governamental importante foi o investimento financeiro direto no valor de U\$23,6 milhões entre 1967 e 1970 na preparação da infra-estrutura industrial do CIA nos municípios de Simões Filho 
e Candeias, contíguos ao município de Salvador, com a construção do Porto de Aratu, de ramais ferroviários $(10 \mathrm{~km})$ e rodoviários $(8 \mathrm{~km})$, de mais de $80 \mathrm{~km}$ de rodovias internas e a implantação do sistema de energia elétrica, telecomunicações e adução e distribuição de água industrial, dentre outros benefícios.

Faz-se mister destacar que um dos fatores preponderantes para a forte migração de capitais da região brasileira mais próspera, o Sudeste, para o Nordeste, foi, sem dúvida, o "excesso planejado" de infra-estrutura produtiva localizada no eixo São Paulo/Rio de Janeiro (REICHSTUL; COUTINHO, 1983). Essa capacidade tecno-produtiva ociosa, caracterizada pela indivisibilidade técnica das plantas e sistemas industriais, seletivamente instalada nessa parte do país ao longo da implementação do "Plano de Metas", do governo Juscelino Kubitschek, efetivou-se segundo uma lógica de antecipação de mercado para as firmas estrangeiras, produtoras de bens de consumo duráveis, que fizeram a opção de investir no Brasil naquela época.

Os volumosos investimentos na região Sudeste foram realizados por agentes privados, sobretudo estrangeiros, e estatal, via endividamento externo. Como resultado disso, e diante da capacidade de consumo do mercado brasileiro, limitada em volume e qualidade, surgiu uma grande crise de realização econômica iniciada a partir de 1962 e que se estende até 1967 (TAVARES, 1986). É em meio a essa crise econômica que se encontra a raiz da explicação de uma menor resistência dos capitais sediados na região Sudeste para se deslocarem para a região Nordeste. Os benefícios econômicos concedidos pelo Governo por meio da SUDENE produziram efeitos substanciais no processo de industrialização do Nordeste e, com isso, possibilitaram a expansão mais rápida do mercado de consumo nacional para os bens de consumo duráveis.

As indústrias que se instalaram na região Nordeste, a partir de então, eram, em grande parte, novas, intensivas em capital e produtoras de bens intermediários; essa base industrial era complementar, portanto, às indústrias localizadas na região Sudeste. Assim, o processo de "desconcentração concentrada" cumpriria sua dupla função: conter a efervescência das massas camponesas na região mais pobre, ao tempo em que forjava a emergência de uma classe social nova com relativa 
capacidade de consumo, via melhor remuneração nas indústrias, ampliando o processo de produção/acumulação e centralização do capital no Brasil, com a instalação de filiais industriais.

É com essa ferramenta indispensável às políticas de atração dos desejados investimentos econômicos, por meio de mecanismo de subsídios líquidos ao capital privado, que a burocracia do estado da Bahia estava se preparando para tentar operar o processo de redenção econômica baiana. Esse processo demoraria mais um lustro para se efetivar e demandaria mais investimentos, dessa vez, estaduais, para a instalação do Centro Industrial de Aratu (CIA) e, posteriormente, também do Complexo Petroquímico de Camaçari (COPEC).

A grave crise econômica instalada no país entre 1962 e 1967 impunha à Petrobras a tarefa mais que necessária de descobrir novas fontes de abastecimento nacional de óleo, para evitar a saída maciça de dólares para importação do produto. Com esse propósito e visando uma possibilidade de atingir sua própria autonomia financeira, a partir de 1964, a diretoria executiva da empresa decidiu executar um vasto programa de investimentos em refino: ampliação de refinarias existentes; aceleração das obras de construção das refinarias Gabriel Passos, em Betim-MG, e Alberto Pasqualini, em Canoas-RS, ambas com capacidade de processar 45 mil bpd; conclusão das Fábricas de Asfalto, uma em Fortaleza-CE e outra junto ao Temadre, na Bahia, em 1965; além da conclusão de numerosos investimentos em dutovias em várias partes do país, aquisição de navios petroleiros, construção e ampliação de terminais de carga e a realização de maciços investimentos na pesquisa e exploração de óleo e de gás natural (MARINHO Jr., 1989; REVISTA PETROBRAS, 1966).

A nova fase de ação da Petrobras veio em resposta à necessidade de o Governo federal não deixar declinar ainda mais o nível da atividade econômica no país. Assim, o setor produtivo estatal foi chamado a participar de maneira decisiva na economia brasileira.

A ação empresarial mais agressiva da Petrobras pós-1964 resultou também na descoberta de novos e maiores campos de petróleo no Recôncavo (Miranga e Araçás, dentre outros) e em Sergipe (Carmópolis), e em incursões na plataforma submarina dos estados de Alagoas e Sergipe. Com isso, surpreendentemente, a meta de atingir a produção de 150 mil bpd até 1970, no Recôncavo, já tinha sido alcançada em 1967.

100. 
Durante esse período, no Recôncavo, as atividades da Petrobras seguiam firmemente na produção de óleo e de gás natural, com as descobertas de novos campos; no refino, com as novas ampliações da RLAM e a construção da fábrica de asfalto; na condução das obras das fábricas de uréia e amônia; na construção de estradas de serviços; em demais obras de construção e de montagem industrial; e em outras demandas por serviços industriais, principalmente, os que atraíam para sua órbita a instalação de novas indústrias - especialmente as metalúrgicas e mecânicas - beneficiando-se dos incentivos fiscais da SUDENE e de outros fundos econômicos.

\section{A implantação do Centro Industrial de Aratu}

Enquanto a Petrobras e o Governo federal não tinham uma decisão definitiva sobre a instalação de um complexo industrial químico na Bahia, tão desejado pelas forças políticas e econômicas regionais, o Governo baiano atuava também em outra frente. Sem descuidar da petroquímica, o Governo estadual investia decididamente em políticas de reestruturação e renovação das indústrias tradicionais (alimentos, fumo, couro, têxtil, bebidas, etc.) e, principalmente, na atração de outros gêneros industriais, notadamente a metalurgia, especialmente a de não-ferrosos e a metalmecânica que abririam novas perspectivas a jusante e a montante.

Ao lado do esforço político e financeiro desenvolvido pelo Governo do estado e da união para promover o desenvolvimento econômico baiano, foi igualmente importante a reforma administrativa realizada pelo Governo estadual, na administração Lomanto Junior (1963-1967), que resultou na criação do Desembanco em 1966. Essa reforma já vinha sendo preparada desde 1955 na administração de Régis Pacheco, quando foram dados os primeiros passos em direção ao planejamento, com a criação da Comissão de Planejamento Econômico (CPE) e demais órgãos de fomento econômico que foram sendo constituídos nas administrações seguintes. A reforma administrativa do governo Lomanto Junior teve como pressuposto um esforço de modernização do aparelho administrativo estadual, com vistas à aplicação mais racional dos recursos públicos orientados para o desenvolvimento regional.

Para dar uma dimensão da robustez do esforço financeiro e político do Governo estadual, no sentido de produzir as externalidades para atrair indústrias para o CIA, sublinha Viana Filho, ex-governador: 
Até 1967 a Bahia tinha pouco mais de 210.000 cruzeiros [cerca de U\$ 79 milhões] de investimentos aprovados pela SUDENE. No período de 1967/1970 foram aprovados 2.000.000 [quase U\$ 440 milhões] [...]. O que significa que dos investimentos aprovados pela SUDENE, nos seus dez primeiros anos de existência 90\% o foram entre 1967 a 1970. E se antes de 67 a Bahia tinha apenas $36 \%$ do concedido pela SUDENE, situando-se depois de Pernambuco, em 1970 veio a ocupar o primeiro lugar com 45\% dos projetos aprovados.

[...] Em síntese, tínhamos, em 1970, 25 empresas em plena produção; 37 em fase de implantação; e 125 com carta de opção (VIANA FILHO, 1984, p. 30).

No estudo realizado por Sampaio, F. (1974), é demonstrado o rompimento da vinculação antes existente entre a indústria baiana e o setor agropecuário, a partir do processo de industrialização apoiado pela SUDENE. As indústrias localizadas no CIA, em suas adjacências e na área industrial do município de Salvador, têm como matérias-primas e insumos básicos os minerais não-metálicos, principalmente o petróleo.

$\mathrm{Na}$ análise da procedência das matérias-primas e insumos utilizados pelas indústrias localizadas na área do CIA referida, a maior parte é adquirida no próprio estado da Bahia, seguido da região Sudeste, como mostra a Tabela 2. Mas, dependendo do tipo de indústria, dos produtos processados e de a mesma ter passado por ampliação ou modernização, a parcela de matéria-prima pode aumentar ou diminuir. Sampaio, F. constata ainda que:

\begin{abstract}
Efetivamente, em média, tão somente $28,9 \%$ da produção das empresas novas destinam-se ao mercado regional (Norte e Nordeste), neles incluído o baiano, enquanto a maior parcela das vendas se orienta para outros mercados, notadamente o do Sudeste do país. No que diz respeito às indústrias em ampliação e modernização, a dependência de mercados extraregionais é menor (SAMPAIO, F., 1974, p. 85).
\end{abstract}

\title{
Tabela 2
}

CIA: PERCENTUAL DO VALOR DAS MATÉRIAS-PRIMAS E MATERIAIS SECUNDÁRIOS DAS EMPRESAS NOVAS E EM AMPLIAÇÃO/MODERNIZAÇÃO DO SISTEMA SUDENE, DE ACORDO COM A PROCEDÊNCIA - 1963/1973

\begin{tabular}{|l|c|c|c|c|c|c|}
\hline \multirow{2}{*}{$\begin{array}{c}\text { Grupos de } \\
\text { Indústrias }\end{array}$} & \multicolumn{5}{|c|}{ Procedência } & \multirow{2}{*}{ Total } \\
\cline { 2 - 6 } & Bahia & $\begin{array}{c}\text { Nordeste } \\
\text { sem a Bahia }\end{array}$ & $\begin{array}{c}\text { Sudeste e } \\
\text { outros estados }\end{array}$ & $\begin{array}{c}\text { Não- } \\
\text { especificados }\end{array}$ & Exterior & \\
\hline Novas & 48,0 & 9,0 & 26,9 & 1,6 & 14,5 & 100,0 \\
Tradicionais & 58,6 & 16,2 & 15,6 & 0,0 & 9,6 & 100,0 \\
Dinâmicas & 46,1 & 7,6 & 29,0 & 1,9 & 15,4 & 100,0 \\
Ampliação/ & & & 12,5 & 0,0 & 3,6 & 100,0 \\
Modernização & 68,6 & 15,3 & 0,5 & 0,0 & 14,0 & 100,0 \\
Tradicionais & 81,0 & 0,5 & 4,5 & 0,0 & 0,9 & 100,0 \\
Dinâmicas & 65,4 & 19,2 & 14,5 & 0,0 & \\
\hline
\end{tabular}

Fonte: SAMPAIO, F., 1974, p. 84.

102. GeoTextos, vol. 3, n. 1 e 2, 2007. Cristóvão Brito 89-116 
Esse fato revela a natureza funcional e integrada dos capitais centralizados nas regiões Sudeste e Sul que se deslocaram para a região Nordeste em busca de maior valorização. Indica ainda o tipo de indústria que se instalou na Bahia e na região Nordeste, que é basicamente produtora de bens intermediários, complementares às indústrias de bens finais, localizadas no Sudeste-Sul.

Com o funcionamento do CIA, a Petrobras constituía-se em uma grande compradora de parcela significativa da produção de algumas indústrias sidero-metalúrgicas e metalmecânicas, localizadas nesse centro industrial e na cidade de Salvador. A partir da década de 1970, as ações da Petrobras no Recôncavo atrairiam grandes indústrias metalmecânicas e de engenharia, para o fornecimento de peças e componentes para montagem e manutenção de plataformas marítimas, sondas e outros artefatos para pesquisa, produção, transporte e industrialização do óleo e do gás, demandando um aumento significativo das firmas de usinagem e montagem industrial (FIEB, 1995).

Ainda na primeira metade dos anos 1970, o Brasil estava envolto na crise de abastecimento do petróleo nacional e precisava fazer prospecções na plataforma continental; com a crise do petróleo de 1973, contudo, muitas companhias ocidentais tiveram de buscar outras alternativas ao petróleo árabe, ocupando todas as plataformas de aluguel no Mar do Norte e na região do Alaska (MARINHO Jr, 1989). Tal fato levou a Petrobras a fazer encomendas de plataformas de petróleo no Brasil; algumas delas foram construídas na Bahia, por indústria instaladas no CIA, bem como tanques para armazenamento de óleo, que eram bastante requisitados na mesma época.

Para a sidero-metalurgia do aço, com a implantação da Usina Siderúrgica da Bahia (USIBA), embora a Petrobras fosse um grande cliente, seu maior mercado era a indústria da construção civil, devido ao processo de expansão rápida do mercado de imóveis de Salvador, no início dos anos 1970, quando a cidade entrou em processo de metropolização. A expansão da indústria da construção civil de Salvador, especialmente, a de habitações, contribuiu também para ampliar a indústria de cimento e de minerais não-metálicos, que, entre outras, passaram a fornecer a maior parte dos insumos, antes quase todo importado da região Sudeste (FIEB, 1995). 
Um desenvolvimento ainda maior no segmento metal-mecânico ocorreria ao longo dos anos 1970, durante o processo de instalação do COPEC, ocasionando grande demanda de vários tipos de artefatos industriais e, inclusive, para sua manutenção.

Contudo, essas atividades ainda não representavam nenhuma certeza na consolidação de um desenvolvimento industrial robusto da Bahia, tendo em vista o fato de os interlocutores regionais da Petrobras já anteverem a escassez do petróleo do Recôncavo em pouco tempo, segundo o ritmo crescente de sua extração.

O esgotamento do petróleo nos campos do Recôncavo e suas conseqüências negativas para os investimentos da Petrobras na Bahia constituíam o maior temor dos articuladores para a instalação da indústria petroquímica na Bahia. No período pós-1964, os mentores da instalação da indústria petroquímica na Bahia tinham como interlocutores os altos escalões do Governo federal e a direção da Petrobras, como ficou patente nas palavras de Rômulo Almeida, em 1972, durante a realização do Simpósio Franco-Brasileiro sobre a Indústria Petroquímica, em Salvador:

O último aspecto a aflorar é o da reserva dos recursos de óleo e gás para a indústria petroquímica. Por enquanto, dispomos de reservas muito pequenas. seria sábio esgotá-las na política tradicional de economizar divisas? Por várias razões diríamos que não. Primeira, os recursos são escassos e assim, por motivo de segurança, devemos reduzir sua exploração; segunda, sua utilização em petroquímica é muito mais vantajosa; terceira, o óleo baiano tem condições especiais para a petroquímica; [...].

Portanto, é bem avisada a política da PETROBRAS de ir reduzindo a produção nacional, do mesmo passo que elevando a taxa de recuperação das jazidas. Mas nos atreveríamos a submeter que, nas condições presentes do Brasil e do mundo, essa política se deve explicitar no sentido de reserva de recursos para a petroquímica (ALMEIDA, 1973, p. 29).

O sinal positivo para a instalação da indústria petroquímica na Bahia saiu finalmente em 1968, com a autorização do CNP, para a Petrobras operar também no ramo petroquímico, com uma subsidiária, a Petrobras Química S/A (Petroquisa). Porém, até esse momento, nada assegurava a efetivação de grandes investimentos petroquímicos na Bahia, além do COPEB. Com isso, os capitais regionais, ávidos por uma nova forma de reprodução mais segura e previsível continuavam de fora da nova indústria que timidamente surgia na Bahia. O núcleo petroquímico do COPEB teve um custo estimado 
de cerca de U\$ 26 milhões, financiado pelo Banco Nacional de Desenvolvimento Econômico (BNDE) e pela Petrobras.

No município de Camaçari, próximo ao COPEB, entre 1968 e 1970, aproveitando os incentivos fiscais da SUDENE e o apoio financeiro do BNDE e dos demais órgãos de fomento econômico, bem como a oferta de matérias-primas fornecidas pela Petrobras, além da fábrica de fertilizantes, também já se encontrava em operação duas fábricas de cerveja, duas indústrias químicas e uma de minerais não-metálicos, mais três empreendimentos estavam em construção e outros três estavam à espera de autorização pela Comissão de Desenvolvimento Industrial (CDI).

Como uma medida de centralização do Governo federal, todos os projetos industriais, para serem implantados, teriam de passar pela avaliação do CDI (criado 1964), pois esse órgão é que aprovava a autorização das concessões dos benefícios governamentais a serem utilizados pelas empresas; o CDI era subordinado ao Ministério da Indústria e Comércio (MIC). Antes de serem analisados pelo CDI, os projetos eram submetidos aos respectivos Grupos Executivos (criados também em 1964), para apresentarem as devidas orientações no sentido de uma melhor performance industrial de acordo com os interesses do Governo.

\section{A luta pelo pólo petroquímico da Bahia}

O CIA estava praticamente consolidado na virada para a década de 1970. Mas, por outro lado, a grande ambição industrial do Governo baiano e dos grupos econômicos e políticos regionais era a instalação de um grande complexo industrial químico, que ainda seria postergado por mais alguns anos, até que a tecnoburocracia petrolífera tivesse reunido as condições suficientes para o exercício do controle sobre o desenvolvimento desse ramo industrial no Brasil, uma vez que a expansão do mercado brasileiro de produtos petroquímicos crescia a uma taxa média anual aparente de quase 250\% entre 1960 e 1970 (Tabela 3) e a tecnoburocracia petroleira não admitia o domínio do mercado brasileiro pelas companhias multinacionais. 
O controle do desenvolvimento da indústria petroquímica no Brasil era um pressuposto que servia, tanto para evitar o monopólio das firmas estrangeiras, como para colocar em prática a própria estratégia autonomista de expansão da Petrobras. Claro estava que essa intencionalidade rebelde da tecnoburocracia do petróleo, associada a uma outra não menos importante, a do BNDE, que também já desfrutava de certa autonomia relativa (MARTINS, 1985), contrariava frontalmente a já declarada determinação política do Governo, de incentivar o desenvolvimento da indústria petroquímica, preferencialmente, o capital privado nacional em associação com as firmas estrangeiras.

\section{Tabela 3}

BRASIL: CONSUMO APARENTE, PRODUÇÃO E IMPORTAÇÃO (T) DOS PRINCIPAIS PRODUTOS QUÍMICOS E PETROQUÍMICOS - 1960/1970

\begin{tabular}{|l|l|l|l|l|l|l|}
\hline \multirow{2}{*}{ Classe de Produtos } & \multicolumn{2}{|c|}{ Consumo aparente } & \multicolumn{2}{c|}{ Producão } & \multicolumn{2}{c|}{ Importacão } \\
\cline { 2 - 7 } & 1960 & 1970 & 1960 & 1970 & 1960 & 1970 \\
\hline Inorgânicos & 570.893 & 1.187 .134 & 359.730 & 965.950 & 187.699 & 221.192 \\
\hline Fertilizantes & 298.734 & 998.566 & 126.837 & 231.950 & 213.687 & 927.020 \\
\hline Plásticos/Plastificantes & 44.645 & 314.690 & 41.547 & 214.152 & 4.149 & 100.295 \\
\hline Fibras sintéticas & 45.931 & 103.442 & 45.500 & 90.262 & 433 & 14.074 \\
\hline Elastômeros/ & 15.834 & 132.981 & - & 124.901 & 22.248 & 12.968 \\
\hline $\begin{array}{l}\text { Negro de fumo } \\
\text { Detergentes sintéticos }\end{array}$ & 1.374 & 21.400 & 1.374 & 21.400 & - & - \\
\hline Solventes orgânicos & 202 & 18.687 & 20 & 14.948 & 299 & 3.739 \\
\hline $\begin{array}{l}\text { Matérias-primas p/ } \\
\text { fertilizantes naturais }\end{array}$ & 1.226 & 514.343 & - & 260.600 & 1.562 & 253.743 \\
\hline Intermediários em geral & 20.011 & 474.892 & 1.500 & 310.948 & 10.654 & 176.985 \\
\hline Primários & 343.291 & 880.341 & 413.930 & 799.205 & 2.620 & 81.301 \\
\hline TOTAL & 1.342 .141 & 4.646 .476 & 990.438 & 3.034 .316 & 443.351 & 1.791 .317 \\
\hline
\end{tabular}

Fonte: Organizada por Cristóvão Brito, com base em: Petróleo e Petroquímica, 1972, n. 1, p. 46-50.

O grupo político regional organizado no partido governista - Aliança Renovadora Nacional (ARENA) - seguindo o processo de modernização conservadora, reinaugurado a partir de 1964, em vez de continuar se lamentando pelo tratamento recebido do Governo central, requalificou os discursos e as ações, utilizando cada vez mais o recurso do planejamento. Ao lado disso, passou a reconhecer a Petrobras como um agente aliado e não mais como adversário, isso após a empresa ter dado sinais evidentes de comprometimento com a instalação do pólo petroquímico na Bahia, entre 1969 e 1970, com Geisel à frente da Petrobras. 
O Governo estadual liderado por Luiz Viana Filho, um arguto articulador político, antecipou-se ao que certamente seria exigido pelos burocratas do Governo federal e pelos grupos privados nacionais contrários à instalação da indústria petroquímica na Bahia - a viabilidade técnica e econômica do tal pólo petroquímico. Em 1969, o Governo baiano solicitou um estudo detalhado das possibilidades para instalação da indústria petroquímica na Bahia, guiado pela indicação da Missão do Banco Interamericano de Desenvolvimento (BID), da qual participava Rômulo Almeida, para promover o desenvolvimento do Recôncavo.

O projeto, elaborado pela empresa Consultoria e Planejamento (CLAN S.A), teve o apoio financeiro da Financiadora de Estudos e Projetos (FINEP), da Petrobras Química/SA (Petroquisa) e da Petrobras. Além disso, o projeto contou com a colaboração de figuras-chave da tecnoburocracia petroleira, do BNDE e, discretamente, do Ministro do Planejamento Reis Veloso, para não se chocar com a rejeição dos ministros: Delfim Neto, Pratini de Moraes, Dias Leite e Costa Cavalcanti.

Vê-se, dessa maneira, que havia uma solidariedade no âmbito da alta cúpula da Petrobras, do CNP, do BNDE e do CDI/Geiquim, o que contribuiu sobremaneira para desobstruir o caminho que conduziria à instalação da indústria petroquímica na Bahia, diante das dificuldades interpostas pelas facções políticas e econômicas contrárias à realização desse projeto na Bahia. A oposição à instalação dessa indústria na Bahia baseava-se no fato de ser a Bahia um estado periférico e distante do grande mercado de consumo, além dos interesses privados da empresa Petroquímica União (PQU) e de demais grupos nacionais e estrangeiros que perderiam vantagens com a instalação desse pólo petroquímico.

O estudo de viabilidade econômica da indústria petroquímica na Bahia foi concluído e as negociações continuaram com o novo presidente da Petrobras, o general Ernesto Geisel, que era simpático à idéia e tinha planos próprios para a expansão comercial da companhia. Geisel era um profundo conhecedor das questões atinentes ao petróleo, ele foi superintendente da Refinaria Presidente Bernardes-Cubatão (RPBC), e também era um militar que gozava da confiança do presidente da república General Médici. Geisel assumiu o cargo com a exigência de livre atuação nos projetos da empresa, pois, a partir dali, iria articular sua candidatura à Presidência da República (MARINHO Jr., 1989). 
Mesmo com o resultado favorável à implantação da indústria petroquímica no Recôncavo, com o apoio da Petrobras, sua concretização não se deu de maneira pacífica, pois já havia interesses privados consolidados, sendo a maioria ligada a grupos estrangeiros, como escreve $\mathrm{Da}$ Poian:

\begin{abstract}
A inexistência de oferta de matérias-primas petroquímicas no país, a falta de uma definição clara a respeito da petroquímica [...] levou os capitais privados nacionais e estrangeiros a desenvolverem, na década de 50, alguns empreendimentos pioneiros utilizando rotas de produção não-petroquímicas. Surgiram assim: a) em 54, as fábricas de MVC e PVC a partir de acetileno obtido do carbureto de cálcio (Solvay); em 57, uma fábrica de estireno a partir de benzeno carboquímico e eteno obtido do álcool (Koppers/Firestone/Hulls); c) em 58, uma fábrica de polietileno de baixa densidade a partir de eteno obtido do álcool (Union Carbide); d) em 60, uma fábrica de fenol a partir de benzeno obtido na siderurgia (Burne Y Borne).

Ainda em 58, a Petrobras colocou em funcionamento sua fábrica de amônia e fertilizantes, iniciou o fornecimento de eteno e propeno e deu início ao projeto da fábrica de borracha sintética [...] As empresas estrangeiras adaptaram suas instalações para utilização de matérias-primas petroquímicas ou lançaram-se a novos empreendimentos, como uma fábrica de metanol a partir de óleo combustível (Borden Chemicals), uma fábrica de negro de fumo a partir de resíduo aromático importado (Columbia Carbo-Celanese), uma fábrica de isopropanol e acetona a partir de propeno (Rhone-Poulenc), e uma fábrica de polietileno de alta densidade (Solvay), a qual teve que recorrer ao eteno obtido do álcool devido à sua localização e à insuficiência da produção de Cubatão (DA POIAN, 1981, p. 29-30).
\end{abstract}

Mais tarde, após as devidas correções feitas pelo Governo na política do setor petroquímico, determinando sua exploração pela livre empresa, criou-se um ambiente político favorável à atuação dessas organizações. Ao lado disso e de olho na expansão do mercado brasileiro de produtos petroquímicos, os diretores da UNIPAR (uma holding que controla a PQU), já cientes da intenção da Petrobras/BNDE de construir um pólo petroquímico na Bahia, contra-atacavam atraindo o apoio da Petrobras e do BNDE à criação de uma área de mercado exclusiva para os produtos da PQU e também tentando sustar a efetivação do pólo petroquímico do Nordeste.

Geisel, na presidência da Petrobras, contrariava abertamente a antiga política do Governo federal e dos nacionalistas centralistas, de evitar comprar petróleo no exterior, também dava sua colaboração para a construção do pólo da Bahia. Sem desprezar a pesquisa do óleo no próprio país, mas, devido ao custo mais barato de sua aquisição no exterior, o presidente da companhia orientava a compra da maior parte do óleo refinado no Brasil em fontes externas, até 1973, quando os países exportadores de 
petróleo decidiram elevar o preço do barril de petróleo de U\$ 3,05 para U\$ 11,65 em 1974.

A política de a Petrobras adquirir petróleo no estrangeiro também favorecia ao plano de não esgotar as limitadas reservas de óleo do Recôncavo. No mesmo sentido, Geisel deu seqüência à ampliação da RLAM (a exemplo das demais refinarias estatais), cuja capacidade de refino foi elevada de 48 mil bpd, em 1966, para 77,5 mil bpd, em 1970, com projetos de novas ampliações até 1978, para mais de 130 mil bpd, quando o pólo petroquímico da Bahia entraria em operação. Assim, a RLAM atingiria capacidade de refino suficiente para produzir matérias-primas petroquímicas em escala comercial.

Após várias ações protelatórias acolhidas pelos ministros pró-PQU, a decisão final da implantação do segundo pólo petroquímico somente sairia em 1971, depois do resultado favorável de um novo estudo contratado pelo MIC para avaliar a viabilidade técnica e econômica da instalação do segundo pólo petroquímico na Bahia (VIANA FILHO, 1984; SUAREZ, 1986).

A despeito dos subsídios econômicos oferecidos pela SUDENE, das linhas de financiamento do BNDE, dos benefícios fiscais e creditícios concedidos pelo Governo baiano e do acesso fácil e seguro às fontes de matérias-primas regionais, de custo inferior a uma localização no eixo São Paulo/Rio de Janeiro, o fator determinante para a consolidação do projeto do COPEC foi, sem dúvida, a adoção da fórmula política de organização acionária das empresas, segundo o modelo tripartite, já utilizado no pólo de São Paulo.

Em novembro de 1972, foi constituída a Companhia Petroquímica do Nordeste (Copene), uma subsidiária da Petroquisa que assumiria a Central de Matérias-Primas, a Central de Utilidades e a Central de Manutenção. Ainda no fim desse ano, teve início o processo de organização das empresas de segunda e terceira gerações e os respectivos formatos para operação no COPEC.

Nas negociações de organização das empresas de produtos de segunda geração, funcionou o modelo tripartite de participação acionária, cuja base era formada por $2 / 3$ de capital nacional ( $1 / 3$ privado e $1 / 3$ estatal) e $1 / 3$ pelo capital estrangeiro. As firmas privadas também se obrigariam a adquirir participação acionária na Copene, como uma estratégia da estatal 
para garantir o compromisso com a empresa, fato capital às partes (ARAÚJO; DICK, 1974). O COPEC entrou em operação em 1978.

Concomitantemente ao processo de industrialização em alguns municípios que comporiam a Região Metropolitana de Salvador (RMS), oficialmente definida em 1973, desenvolveu-se também um processo de urbanização articulado e complementar ao primeiro.

Ao longo do tempo as ações da Petrobras no Recôncavo atraiam para sua órbita uma grande quantidade de população em busca de emprego na refinaria e/ou nos campos de exploração, e também nas empresas que lhe prestavam serviços. A construção da refinaria, suas ampliações posteriores e a existência de um grande campo de petróleo implicaram na atração de grande contingente que foi se instalando na vila de Candeias, cujo distrito antes de sua emancipação política do município de Salvador, em 1958, tinha 3.607 habitantes e, em 1960, o novo município já contava com 18.484 pessoas e, dentre essas, 12.500 habitavam na cidade. Situações semelhantes de ampliação da população municipal e do crescimento da população urbana ocorreram noutros municípios petrolíferos como evidencia Souza (1976):

\footnotetext{
Nos anos que vão de 1950 a 1965, correspondentes ao período em que a Petrobras mais recrutou mão de obra, foi significativa a parcela de migrantes absorvida por vários dos municípios onde a empresa atuava, principalmente por Candeias, S. Francisco do Conde e Camaçari (SOUZA, 1976, p. 46).
}

A orientação preferencial dos fluxos de população para as cidades dos municípios petrolíferos próximos a Salvador deve-se principalmente à conjugação das seguintes condições: a construção da rede de estradas construída na área de operações da Petrobras, que ao mesmo tempo favorecia as necessidades de transporte da empresa, a circulação de mercadorias e também o fluxo de população do campo para as cidades e de uma cidade para outra; a grande oferta monetária em circulação, em forma de salários pagos aos milhares de empregados diretos da Petrobras na Bahia, que por volta de $1970^{2}$ era cerca de 16.000 (SILVA, 1972) e tantos outros das firmas terceirizadas e dos gastos diversos da companhia; e a reestruturação fundiária ocorrida na área de exploração petrolífera, quando a Petrobras passou a adquirir terras por meio de desapropriação para a realização de seus serviços.

110. 
Além do crescimento demográfico, que originou uma importante bacia de mão-de-obra à disposição da companhia, iniciou-se também o processo de urbanização da população como um modo de vida. A expansão das atividades da Petrobras na zona petrolífera induziu o processo de crescimento urbano num nível mais dinâmico, acompanhado do fenômeno da urbanização que ocorria de maneira mais lenta. Esses núcleos urbanos passaram a desempenhar novos papéis, principalmente em decorrência das demandas da Petrobras. A esse respeito Azevedo (1959) destaca:

\begin{abstract}
A Petrobras faz o grosso de suas compras na capital do estado; todavia compra algum material de construção, alimentos, medicamentos [...] e outros artigos miúdos nas cidades próximas aos seus serviços [...]. [Em Candeias], ali como noutros "campos" compram-se verduras, ovos, aves, carne, farinha produzidos nos arredores pelo estímulo da demanda de tantos consumidores novos (AZEVEDO, 1959, p. 14).
\end{abstract}

A massa de dinheiro em circulação, em forma de salários e gastos diversos da Petrobras, mormente nas cidades mais próximas dos campos de produção e da refinaria, provocou, em pouco tempo, considerável alta dos preços nos mercados locais, sobretudo nos itens habitação, alimentação, vestuário e serviços pessoais. Além disso, implicou segmentação social e mudança de hábitos na população, como grifa Azevedo:

[...] aumenta o número de bares, sorveterias, farmácias, lojas de miudezas, fazendas, artigos de toilette; surgem casas de artigos elétricos, rádios, móveis, fogão a gaz e a querozene, bicicletas, até geladeiras, tudo denunciando um processo intensivo de urbanização com toda sua fenomenologia sócio-cultural (AZEVEDO, 1959, p. 14).

A magnitude dos recursos gerados anualmente pela Petrobras na Bahia era tão importante que a empresa programou um investimento, em suas atividades no Recôncavo, igual à receita total orçada do próprio estado da Bahia para o exercício de 1959, que foi da ordem de Cr\$ 3 bilhões, ou seja, quase U\$ 20 milhões (BARROSO, 1959).

O aumento da arrecadação de receitas nos municípios petrolíferos permitia às municipalidades implantar e/ou melhorar a infra-estrutura pública: pavimentação de ruas, rede de energia elétrica e de abastecimento de água e saneamento além de outros serviços públicos coletivos. A vida simples das populações dessas cidades se abria à complexidade do novo modo de vida que já começava a se apresentar. 
A instalação do CIA, seguida do COPEC $^{3}$ e do Complexo do Cobre, induziu o aumento exponencial da população, sobretudo, na cidade de Salvador, contribuindo para dar início ao processo de metropolização dessa cidade. Nessa perspectiva, na administração do então prefeito da capital, Antônio Carlos Magalhães, foi implementado um plano de reestruturação da cidade, iniciado com a privatização das terras municipais, no sentido de dinamizar o mercado de habitação (reforma urbana de 1968) ${ }^{4}$ seguido da abertura das Avenidas de Vale (proposta pelo urbanista Mário Leal Ferreira) e da localização seletiva de infra-estrutura pública em áreas específicas da cidade, entre outras ações, com o fim de buscar atender as novas funções urbanas demandadas pela industrialização nos municípios em seu entorno. As ações de reestruturação urbana da capital, de certa maneira, tiveram seqüência nas administrações posteriores.

Ao lado de todos os elementos ligados à urbanização nos municípios da RMS, em 2000, destaca-se a predominância da influência urbana, que pode ser representada pelo consumo de energia elétrica não residencial e exclusive iluminação pública, atingindo, em media, 99,7\% do consumo de energia nas classes: industrial, comercial e serviços, no total de consumo para as mesmas classes no estado da Bahia. Do mesmo modo, em 2000, a RMS consumiu 54,5\% da energia elétrica na classe industrial fornecida exclusivamente pela distribuidora de energia elétrica, a Companhia de Eletricidade da Bahia, sem contar com a energia elétrica fornecida diretamente pela empresa geradora de energia elétrica - a Companhia de Energia Elétrica do São Francisco.

Contudo, todas essas importantes transformações ocorreram acompanhadas de problemas socioespaciais graves, surgidos em meio ao próprio processo de estruturação do espaço na RMS, relacionados com: a concentração da renda, que passou de 57\%, em 1991, para 61\%, em 2000; os baixos salários, expressos na renda média mensal das pessoas formalmente empregadas em 2000, de U\$ 650,00 para os brancos e de U\$ 230,00 para negros e mestiços; a taxa de analfabetismo funcional entre a população de 15 anos e mais, em 2001, que era de 18,2\%; e a percentagem de domicílios que não possuíam esgotamento sanitário, que era de 11,2\%, em 2001 (de um total de 829.344 domicílios com uma população total de 3.093.260 habitantes).

112. GeoTextos, vol. 3, n. 1 e 2, 2007. Cristóvão Brito 89-116 


\section{Considerações finais}

O balanço dos episódios da instalação do CIA e depois do COPEC e as transformações na urbanização na RMS serve para ilustrar o processo de organização e reprodução de uma parte do espaço geográfico, sob a liderança exclusiva de uma grande corporação, a partir do início da década de 1960 até a década de 1990.

Durante esse período, pode-se afirmar que a Petrobras, por meio da interação de suas ações, aliada aos demais agentes com interesses regionais, foi capaz de estruturar e desenvolver uma nova porção do espaço geográfico no Recôncavo, e, ao mesmo tempo, induzir um processo de transformações fundamentais na estrutura social, política, técnico-produtiva, econômica e espacial, que transbordou para além dos limites da RMS. Contudo, a organização e a gestão desse subespaço pela Petrobras ocorreram combinando seus interesses diretos com os interesses dos demais agentes envolvidos.

\section{Notas}

${ }^{1}$ Texto publicado originalmente na Revista Desenbahia, Salvador, v. 1, n. 1, p. 37-57, set., 2004.

2 Ao longo do tempo a Petrobras foi diminuindo a quantidade de funcionários diretos na Bahia até chegar no ano 2000, quando o número de empregados lotados na Sede Regional da Bahia era de 5.051 trabalhadores (BRITO, 2004).

${ }^{3}$ Atualmente o COPEC evoluiu de um complexo industrial químico e petroquímico para um sentido mais amplo de pólo industrial, com a instalação e operação de diversas grandes indústrias a exemplo do complexo automotivo da Ford, fábricas de pneus, plásticos, tintas e vernizes, indústrias farmacêuticas etc.

${ }^{4}$ Com a Lei de Reforma Urbana de 1968 ,decretada pela Prefeitura Municipal de Salvador, que privatizou as terras de propriedade municipal, havia uma intenção subliminar que era exatamente a monopolização privada da terra adquirida por meios pouco claros e a baixo custo, que seriam beneficiadas com obras públicas à espera de maior valorização em um mercado imobiliário promissor (RIBEIRO; DEBEFFE, 1979; BRITO, 2005).

\section{Referências}

ALMEIDA, Rômulo. Petroquímica na economia nacional. Petróleo e Petroquímica, Rio de Janeiro, p. 22-29, maio/jun., 1973. 
ARAÚJO Jr, José Tavares de; DICK, Vera Maria. Governo, empresas multinacionais e empresas nacionais: o caso da indústria petroquímica. Pesquisa e Planejamento Econômico. Rio de Janeiro, v. 4, n. 3, p. 629-654, dez. 1974.

“Conferência do petróleo”. A Tarde, Salvador, 20 jan. 1959. Suplemento Especial.

AZEVEDO, Thales de. Problemas sociais da exploração do petróleo no Recôncavo. A Tarde, Salvador, 20 jan. 1959. Suplemento Especial, p. 9-10; 14; 19-20.

; LINS, Edilberto Quintela Vieira. História do Banco da Bahia - 18581958. Rio de Janeiro: José Olympio, 1969.

BAHIA. Secretaria do Planejamento, Ciência e Tecnologia/Conselho de Desenvolvimento do Recôncavo. Estudos básicos para o projeto agropecuário do Recôncavo: estrutura agrária. Tomo III. Salvador: BAHIA, (197-). 93 p.

BARROSO, Geonísio Carvalho. Aspectos econômicos da produção do petróleo no Brasil. In: Economia do Petróleo. Rio de Janeiro: Instituto Brasileiro do Petróleo, 1959, p. 33-60.

BRITO, Cristóvão de Cássio da Trindade de. A estruturação do mercado de terra urbana e habitação em Salvador-BA a partir de 1970. Geotextos, Salvador, v. 1 , n. 1, p. 51-80, dez., 2005.

A Petrobras e a gestão do território no Recôncavo Baiano. Tese (Doutorado em Geografia) - Centro de Filosofia e Ciências Humanas, UFSC. Florianópolis, 2004.

CASTRO, Antônio Barros de. 7 ensaios sobre a economia brasileira. 2. ed., v. 2. Rio de Janeiro: Forense Universitária, 1975. 248 p.

COHN, Amélia. Crise regional e planejamento: o processo de criação da SUDENE. 2. ed. São Paulo: Perspectiva, 1978. 165 p. (Col. Debates - Ciências Sociais)

COSTA PINTO, Luiz de Aguiar. Recôncavo: laboratório de uma experiência humana. Rio de Janeiro: Centro Latino-Americano de Pesquisas em Ciências Sociais - CLACSO, 1958. 149 p.

DA POIAN, Pedro Paulo. A presença do Estado e da empresa privada na petroquímica brasileira. Petro \& Química, São Paulo, ano 4, n. 32, p. 28-36, Abril, 1981.

FIEB-Federação das Indústrias do Estado da Bahia. Industrialização na Bahia: construindo uma nova estratégia. Salvador: FIEB, 1995. 97 p. 
GUIMARÃES, Antônio Sérgio Alfredo. A formação e a crise da hegemonia burguesa na Bahia - 1930 a 1964. 1982. 200 p. Dissertação (Mestrado em Ciências Sociais) - Faculdade de Filosofia e Ciências Humanas, UFBA. Salvador.

MARINHO Jr., Ilmar Penna. Petróleo: política e poder (um novo choque do petróleo?). Rio de Janeiro: José Olympio, 1989. 468 p.

MARTINS, Luciano. Estado capitalista e burocracia no Brasil pós-64. Rio de Janeiro: Paz e Terra, 1985. 265 p. (Col. Estudos brasileiros - Política, v. 82)

OLIVEIRA, Francisco de. Elegia para uma re(li)gião: SUDENE, Nordeste, planejamento e conflito de classe. 5. ed. Rio de Janeiro: Paz e Terra, 1987. 132 p. (Estudos sobre o Nordeste, v. 1)

REICHSTUL, Henri Philippe; COUTINHO, Luciano G. Investimento estatal 19741980: ciclo e crise. In: Desenvolvimento capitalista no Brasil: ensaios sobre a crise. São Paulo: Brasiliense, v. 2, p. 38-58, 1983.

REVISTA PETROBRAS. Rio de Janeiro, n. 221, p. 11-19, jul./ago., 1966. . Rio de Janeiro, n. 203, p. 34-37, ago., 1963.

RIBEIRO, Elisabete Maise Andrade; DEBEFFE, Charles. Poder público municipal e propriedade fundiária urbana. In: BAHIA. Seplantec/CPE. Habitação e urbanismo em Salvador. Salvador: [s.n], 1979. p. 81-220

SAMPAIO, Fernando Talma. Aspectos da regionalização do desenvolvimento industrial: o caso baiano. 1974. 154 p. Dissertação (Mestrado em Economia) - Faculdade de Ciências Econômicas, UFBA. Salvador.

SAMPAIO, Nelson de Souza. Eleições bahianas. Revista Brasileira de Estudos Políticos, Belo Horizonte, n. 8, p. 134-161, abri., 1960.

SANTOS, Valdemiro Lopes dos. A pecuarização do Recôncavo fumageiro: o caso de São Gonçalo dos Campos-Ba. 1990. 251 f. Dissertação (Mestrado em Geografia) - UFPE, Recife, 1990.

SANTOS, Milton. A rede urbana do Recôncavo. Salvador: Imprensa Oficial da Bahia, 1959. 38 p.

SCHOR, José. Aspectos econômicos da refinação do petróleo no Brasil. In: Economia do petróleo. Rio de Janeiro: Instituto Brasileiro do Petróleo, 1959, p. 61-78.

SILVA, Maria Auxiliadora da. Les migrations pour le reconcave du petroleo, Salvador-BA, Brasil. 1972. 101 f. These (UER de Geographie) - Centre du Geographie Appliqué, Université Strasbourg I, 1972. 
SINGER, Paul Israel. Economia política da urbanização. 8. ed. São Paulo: Brasiliense, 1981. $151 \mathrm{p}$.

SOUZA, Guaraci Adeodato Alves de. A população do Recôncavo baiano. Salvador: Centro de Recursos Humanos da UFBA, 1976. 55 p.

SUAREZ, Marcus Alban. Petroquímica e tecnoburocracia: capítulo do desenvolvimento capitalista no Brasil. São Paulo: HUCITEC, 1986. 242 p. (Economia e Planejamento)

TAVARES, Maria da Conceição. Acumulação de capital e industrialização no Brasil. 2. ed. Campinas: UNICAMP, 1986. 160 p.

VIANA FILHO, Luiz. Petroquímica e industrialização da Bahia - 1967-1971. Brasília: Senado Federal/Centro Gráfico, 1984. 154 p. 